\title{
TRAINING PEER COUNSELLORS AND PROFESSIONALS IN HUMAN SEXUALITY AND FAMILY LIFE EDUCATION
}

\author{
ROBERT J. NAGGE \\ Michener Centre
}

\begin{abstract}
The training of peer counselors and family life educators has shifted from a medical-biological orientation to the social sciences. In the process the related curriculum has developed from "the facts of life" to the concerns of everyday living. And, the teaching has changed from information giving lectures in a telling style of teaching to an experiential format in a participative, student-centered style of teaching. Important milestones during the past three decades are described to indicate the trend leading to the use of human sex. uality education as a vehicle for personal growth and self actualization.
\end{abstract}

The publication of the now famous Kinsey Studies $(1948,1953)$ in the late Forties and early Fifties heralded a new era. The research not only legitimized human sexuality as an appropriate area of study, but also reflected a broad interest in the topic. At about the same time, Ellis (1966) was developing brave perspectives on the topic, and when Masters and Johnson (1966) published their first work, the field broadened quickly. James McCary (1967) started teaching human sexuality at the college level, and published one of the first texts for a college level course. The media increased its attention to this aspect of human relationships as more magazines and films capitalized on the Playboy image, and even "respectable" magazines were opening their pages to articles and discussions. In the Sixties, sex, it seems, had finally gone public.

Concurrently, Sex Education, Family Life Education and courses with other similar titles, became an issue in school systems. A typical response was the formation of an Interprofessional Study Committee on Family Life Education in Winnipeg School Division 1 (Guest, 1966). This committee was asked to "consider the whole question of sex and family life education and report its conclusions and recommendations to the School Board." (In retrospect, a rather momentous task!) Similarily, it was reported that "Community Agencies, youth organizations, churches and schools are all scurrying to institute programs of sex education" (Luckey, 1967).

\footnotetext{
Attaar's Notez The views expressed in this article are the author's and are not represented as those of the Aichener Centre or Department of Social Services and Community Healah, Province of Alberta.
} 
As Human Sexuality and Family Life Education were introduced to the schools, it was seen to be a "serious concern and not just to adolescents and their parents, but also to persons in the teaching and helping professions" (Luckey, 1967). The "by whom" question burned brightly along with the "whats, whens and hows." Referring to college courses on sexuality during this time Harold Lief describes them as often "overly intellectualized and sterilized. Though it is hard to imagine sex as dull, it often was" (Diamond \& Karlow, 1980).

\section{PIONEERING PROGRAMS}

Early programs focused primarily on biological issues-anatomy and the physiology of reproduction. Where relationship issues were discussed, it was often in the context of traditional roles, and taught in home economics classes, Information was couched in the safety of technical terminology, and idealistic models were introduced to promulgate the romantic fantasy of "living happily ever after." Question boxes were used to elicit questions (and perhaps filter out "tough questions"). A predominant fear raised by teachers at the time was, "What do I say if students ask if I have done it?" (My first exposure to Sexuality Education was in a college Biology class where a film was shown on an Amoebat reproducing - a long way from the needs and interests of a confused, horney adolescent!!)

Educators found themselves torn between the needs expressed by students, the apprehensions of parents, and the whims and anxieties of the political leaders. Response to these concerns, and teacher fears and apprehensions, were varied. Some teachers latched onto the "canned" programs which featured recordings and film strips; some followed a straight biology approach; some adopted an aloof distancing stance which kept students away from their concerns; and some "let it all hang out"-giving control of the content to the students, and responding frankly and openly in an exploring shared search. The last group usually found themselves with much media attention-and reassignment to other teaching areas.

The need for the training of teachers and counsellors moving into this area became apparent. Professionals in all aspects of the helping field were faced with the need to acquire new information, and to overcome the social norms which had dictated, in essence, that "nice people don't talk about sex." Moreover, they were challenged to develop new approaches in their role of factilitating learning and development, because of the feeling and emotion that was associated with sexuality.

Teachers required direction and clarity in curriculum development, since there were seldom curricula available that readily passed parent or School Board intense scrutiny. To involve parents required skills in helping groups in decisionmaking and consensus seeking (Procopia, 1978). Teachers also wanted classroom skills which had a group focus-climate setting, listening, clarifying, aftirming. They wanted structures which focused discussion, in order to highlight the diversity and reflect the similarities and differences of individuals in their classes (Dimock, 1983).

Counsellors, nurses, social workers, and community workers wanted a framework from which they could broaden their knowledge and belief system, so 
as to better accept and understand their clients. Working in the area of Sexuality and Family Life, in a time of emerging alternative life styles, was both scary and exciting for most professionals.

\section{THE SHIFT FROM CONTENT TO PROCESS}

The training challenge for the $70^{\prime}$ 's in this field became helping professionals use themselves as the major component in an education, training or therapy program. This change dictated a shift in emphasis from the "teacher" being the primary focus for learning opportunities, defining content, and assuming primary responsibility for learning (Knowles, 1973). This move from content to relationships was revolutionary, as it meant a radical role shift for the professional from primarily a deliverer of information to that of utilizing the "here and now" of participant beliefs, understandings and behaviour, and linking observations to the knowledge and theory which reflected participants stated learning goals.

Dimock (1983) cites research and principles which speak to the need for active involvement of participants in the planning process, as well as in the "action" of the program. His "personal qualities" in the helping professions (Dimock, 1976) reflect on the need of teachers for self-insight and interpersonal awareness in contrast to additional knowledge of subject matter.

Knowles (1974) provides a model for generalizing goals for the learner which he calls, "Dimensions of Motivation." This model, used as a tool to help learners set directions for themselves as they enter a program, forms a foundation for program design. He also outlines a contractual model which, under the headings of knowledge, understanding, skills, attitudes, values and interests, elicits behavioural outcomes, and suggests appropriate techniques to help meet these goals.

Further, both authors stress the need for a group climate of trust and support in programs, as well as the need for frequent evaluation of progress toward learning goals. Tools for evaluating both climate and learning progress are described in their writings.

This developing shift in learning approaches had a powerful impact on training. For the professionals, the shift identified new skills and knowledge around working with groups. Observation and listening skills were required to augment the understanding of group process. Professionals had to learn to trust the learners, themselves, and the process. They were required to better understand their own beliefs and perceptions, so as to better use their status and power to enhance learning, rather than impede learning by "playing their own piano." Modelling became a powerful tool.

For those who trained the trainers, the above preoccupations were also relevant. The emphasis focused on design skills, so that the structure of programs ensured the intended outcomes expressed by participants. And as members of the learning community, training staff had to add what their experience and knowledge indicated was important, so that learners could priorize trainer goals as well as their own. Traditional roles and assumptions of trainers were constantly being challenged as learners took charge of their own learning episodes. Time was a factor, and the duration of programs lengthened, as did the level of involvement and intensity. Training/learning became a process, and the emphasis moved away from brief information giving sessions. 


\section{AFFECTIVE EDUCATION}

Some very creative methods and techniques were developed to help learners meet their learning goals. For example, paper and pencil tests (Skat, 1971; Bcm, 1974) were used to identify group data, allow participants to experience a range of attitudes, beliefs and behaviours, to develop a repertoire of sexual terminology, and to provide a safe arena to practice use of terminology. Structured case studies, giving background information, as well as stopping at several steps of the intervention, allowed small groups to work through the case, and uncover the myriad of perceptions, myths and beliefs that individuals brought to the group. Values exercises, such as "Alligator River" and its variations, used as a consensus tool, quickly shattered the assumption that everyone sees the world the same way. It also quickly identified the intensity of emotions and feelings tied to beliefs and perceptions, as well as allowing an opportunity to look at how they affected behaviour.

Demonstrations using actual clients, adolescents, or classroom groups became a potent tool. Participant planning for demonstrations-identity goals, considering options, and choosing strategies; and a comprehensive evaluation after the fact (which usually involved participation and feedback from the visiting resource(s)) provided immediate feedback to participants. Demonstrations of sexual history taking, using the form developed by the Kinsey team (Kinsey, 1948), and the short problem focused form (Anon, 1974), allowed participants to react to and critique the event, and to modify to suit their own style and preference. Contracting sessions, using real and immediate sexual and relationship issues from within the group, under the coaching and direction of the training team, demonstrated the potency of the method, and often resolved underlying dynamies in the group. Adolescent groups particularly responded to a contacting structure which allowed them to set sexual limits on developing relationships in a way which was both affirming and freeing. (The "Alphabet" model, in which each letter of the alphabet represented increasing levels of sexual intimacy, was one example. It gave adolescents a comfortable language and frame of reference with which to discuss their feelings, expectations and limits in relationships.)

Structured exercises provided the opportunity to participants to explore their own fantasies, body images, communication styles, and relationship development patterns. For example a "guided fantasy" where the trainers start by establishing intent and participation guidelines and then create a beginning scenario (i.e., ". .. three people are walking down the street ..."). Each participant in turn would build in the scenario, identifying the gender of the trio, their relationship, where they are going, what they will be doing, and what some of the interpersonal issues or decisions are that would be facing them. Each aspect of the developing scenario could be expanded as far as an individual wished to carry it, and then passed on to the next participant for further development. Such an exercise airs a broad range of issues related to interpersonal relationships, expectations, hopes, hesitancies and modeis of resolution.

The foundation for all these structured experiences was not only to allow participants to explore themselves, and understand the rich diversity of others, but also to provide them with tools which they could use in their back home situa- 
tion. The structure generated "here and now" material from the group, and some ways of using the material. "Real stuff" is always the "best stuff" in learning.

Films became a special tool. Since films reflect the director's point of view, reaction is always varied. Films confront both the affective and cognitive domains of the viewer. For many, films constitute a voyage into taboo areas, since explicit sexual activity is usually seen as private and personal. Technical films depicting previously unknown physiological functions such as those developed by Masters and Johnson opened new areas for discussion and learning. Group techniques, (1) to desensitize and prepare watchers; (2) to focus on specific behaviours; and (3) to use films as a foundation to raise additional issues, all helped make films a valuable tool in the training process (Dimock, 1973). Flooding was a common technique to desensitize groups and prepare them for less emotional journeys into the area of Sexuality and Family Relations. ${ }^{2}$

Pre-film planning and post film discussion provided the core for learning - the film was only a triggering tool. A film on sex and relationships in later years, for example, would be preambled by generating the myths and views and perceptions within the group. Watching groups (Dimock, 1973) would be formed, and assigned specific areas to look for in the film. After a short planning session by each watching group, the film would be shown. After the film, each group would organize and share their observations, and the collected observations would be compared to the material which the group had originally generated. Their material would then be linked to research in the area, and a discussion would ensue around how they might use the material in their back home situation.

The behavioural approach to learning in the sexual area proposed by Masters and Johnson (1966) and elaborated on by Anon (1974) was augmented by a creative adaptation of analytic theory presented by Kaplan (1974). Barbach (1976) combined the use of film and small group methods in working with preorgasmic women. Each new development provided ideas for adaptation to both group and one-to-one learning encounters.

Anon's PLISSIT model gave a useful perspective to the helping role in Sexuality. His analysis of what had been helpful to clients in a sample of clientcounsellor relationships in the sexuality field helped clarify the learning process, and his model adapted readily to the training arena. Permission giving, limited information and specific suggestions far surpassed the number of interventions requiring intensive therapy by clients reporting the help they received. The model added to roles which teachers and counsellors could add to their repertoire in working with others.

Clearly, there was a strong shift in focus from an explain/diagnose/prescribe approach to one of the collaboration between clients/counsellors and trainers/learners. The emphasis in trainer role moved from teacher to learning facilitator, from "expert" to "resource", and from using "data" as the primary learning tool to use of "self." For new teachers coming into the field, this represented a profound change in how they saw themselves and their role. And this change identified new skills to add to their professional profiles. 


\section{LEARNERS DESIGN THE EDUCATIONAL PROGRAM}

As the importance of adolescent peers in the sexuality and relationshiplearning process became more recognized, programs which mobilized adolescents were developed, "Peer counsellors" were selected and trained as formal and in. formal resources in High School and communities. Segal's (1979) pioneering work training peer counsellors in a Planned Parenthood Clinic became one of several models adapted for High Schools. Her program was essentially a human relations approach backed up by sexuality information. Goals and directions were set collaboratively. As equal partners, peer counsellors planned the training program, and outlined their learning needs. They learned to listen nonjudgementally, confront constructively, and give clear, if at times overly enthusiastic feedback. They critiqued each others' presentations in a way that reflected the goals of the program rather than in a competitive way. They learned to identify and solve problems, make decisions and plan. They learned to use each other and outside resources in an effective way. Most importantly, they learned to use themselves in working with other adolescents.

A comparable program was established at John Rennie High School in Pointe Claire, Quebec-through the initiative of two counsellors, Don Kinsella and John Gage collaborative arrangements were made with the students and faculty of the Department of Applied Social Science of Concordia University to work as consultants in developing such a program. Student selection and training was planned using Segal's model and about fifteen high school students completed the program. While much of the training was scheduled for regular classroom hours, students were required to be involved in after-class time. Regular supervision was provided by the counselling staff and by the University consultant and assisting students. It seemed a natural follow-up to the school's sexuality education program, which itself was a solid model as evaluated by parents and students. Not surprisingly, initial reaction to Segal's program and to the John Rennie program was skepticism. Recognizing these young people as knowledgeable resources rubbed the grain of the traditional perception of adolescents as confused and flighty. It also dented the perception of "helpers" as highly trained "experts." Adolescent peers responded quickly while other parts of the community responded in a more guarded way. Fortunately, the model of adolescents doing crisis intervention during the early drug years was not forgotten.

In the case of Segal's first group, the effectiveness of the training model is exemplified by many of the first group becoming agency resources, and moving on to schools and clubs, and parent's groups. Some are presently involved in training a "third generation" of new counsellors. The John Rennie program was sustained, and adapted by other schools.

By providing accurate information, helping skills, and understanding of the helping process, rich resources were developed for the adolescent community. And importantly, these young people were seen as acceptable and credible by their peers. Learning and growing were clearly a function of the quality of the relationship established. 


\section{A SUMMARY OF CHANGES}

The past twenty years has seen a drastic change in the training of professionals in the sexuality field. In the Sixties, sexuality information was presented in a didactic way, with a passive audience reacting impersonally. A knowledge of theory, research, and content were the only tools of the "teacher" augmented, perhap 5 by a scintillating delivery style. The animated (or withdrawn) reaction in halls after the fact reflected a greater need. The Kinsey material clearly stimulated interest.

Ellis moved the field along with his style of delivering the message, followed by active and at times abrasive debate. (The latter consumed fully seventy percent of program time!)

It was the pioneer work of Masters and Johnson, Satir and Barbach that shifted the emphasis in training and in therapy to a more collaborative approach to individual change. The trainer/therapist/counsellor was now encouraged to share perspectives and feelings in an active and creative way; all parties were involved in the "process" of discovery and learning.

Those who worked in a training role in the area of sexuality and family life often found themselves wearing, at different times, the three hats usually worn by different consultants. The "expert" hat included being up to date on current readings and research in the sexuality area. The "resource" hat was necessary because of tacit expectation that trainers were aware of the many networks, innovations, and people with particular skills and/or interests. And the "Process" hat was worn constantly as the trainer worked with what was going on in the training groups, using activities and interactions in the group to highlight principles and understandings and enhance their "here and now" personal learnings of the participants.

The development of this field to its present state has not been without stress. Community reactions, social action groups, special interest groups, and a gradual shift in the political climate, all have generated confrontation and highlighted different points of view. Sensitivity to this diversity has been important, and indeed collaborative planning and cooperation has not always been possible. Clearly, there has been much "heat in the kitchen"-but the "heat" has generated more community involvement and lively discussion at a level seldom seen in education. Almost all issues in Sexuality and Family Life Education generate polemics!

There has also been some interesting diversity in the sources of training. As the field developed, traditional disciplines such as Medicine, Sociology and Psychology each saw the field as their domain. Other disciplines-Theology, Anthropology, Philosophy, Psychiatry and Biological sciences highlighted their contribution. What seems to have emerged is a multi-disciplinary approach, with recognition and respect for all contributions. And as disciplines have collaborated, so too have delivery systems. Universities have developed undergraduate and doctoral programs for advanced study and research, and continuing education programs for professional development (the current University of Guelph program would be an example of the latter).

At the same time, community agencies and school boards have established developmental programs for their staff, often in collaboration with the University 
community. Professional bodies such as AASECT in Washington, and A.F.L.E.Q, in Quebec have sought to regulate training and practice with only limited success. Sexuality and family life expression, it seems, is complex to learn about the difficult to control lessons that are apparent throughout history!

As new dimensions of sex and gender take shape in contemporary society, training will be called on to find new and creative ways to incorporate these perspectives into their training plan. New life styles, new social family norms, and changing sex roles, confront professionals on an almost day-to-day basis. There is a growing awareness of ageism, sexism, classism, and racism in films, the literature and research (Wallum, 1977). Teacher awareness of minority students and minority points of view is becoming increasingly important. Counsellor awareness of their own "norms" and biases is especially important as their client base expands. Professionals will increasingly be faced with the need to include ways of reaching the physically and mentally handicapped, and minorities. This will require new knowledge and sensitivity to the experience and self-perception of these learners.

Clearly, the challenge of the 80 's will be the continuing search for new ways to help "helpers" and trainers understand themselves, and to develop new and creative ways to involve themselves in the change process. Design skills which enhance the interpersonal process of learning, and methods which enhance the application of learning to everyday living, appear to be the new frontier.

\section{REFERENCE NOTES}

1. For a discussion on a continuum of approaches, from directive to collaborative, and trainer implications along the continuum, see Brundage and Mackeracher (1980).

2. The National Sex Forum in San Francisco used this technique effectively in early training.

\section{RÉSUMÉ}

La formation des conseillers-pairs et des éducateurs familiaux est passće d'une orientation médico-biologique à une approche issue des sciences humaines. En cours de route, les contenus ont abandonné les "faits de la vie" pour se porter sur les préoccupations de la vie quotidienne. La pratique éducative a elle aussi changé: de l'information donnée sous forme de cours, on en est arrivé à une formation expérientielle via la participation et l'autogestion de l'apprentissage par l'étudiant. On décrit dans cet article les jalons importants de cette évolution au cours des trois dernières décades; on indique aussi la tendance actuelle à utiliser l'education sexuelle pour favoriser la croissance personnelle et l'actualisation.

\section{REFERENCES}

Anon, J.S. (1974). The behavioral trestment of serual problems: Volume t. Honolulu: Enabling Systems Inc.

Barbach, L- (1976). For yolerself: The fulfilment of female sexuality. Garden City, NY: Anchor Books. Bem, S. (1974). The measurement of psychological androgeny, Journal of Consulting Psychology, 42 (2). 155-162.

Brundage, D. \& Mackeracker, D. (1980)). Adull learning principle and their application to progralt planning. Toronto: OISE, 
piamond, M. \& Karlen, A. (1980). Sexaal decisions. Toronto: Little Brown Company.

pintock, H.G. (1973). How to plan staff training programs. Guelph: University of Guelph. (1976). Social intervertion in the helping professions. Montreal: Concordia University.

(1983). Factors in working with groups (2nd Ed.). Guelph: University of Guelph.

Ellis, A. (1966), Sex without guilt. New York: Lancer Books.

Guest, H.H. (1966). A report on family living education. Winnipeg School Division No. 1.

Kaplan, H.S. (1974). The new sex therapy. Montreal: Montreal Book Centre.

Kinsey, A.C., Pomeroy, W.B. \& Martin, C.E. (1984). Sexaal behawior in the fruman male, Philadelphia: W.B. Saunders Co.

Kinsey, A.C., Pomeroy, W. B., Martin, C.E. \& Gebhard, P.H. (1953). Sexual behavior in the human female. Philadelphia: W.B. Saunders Co,

Knowles, M.S. (1973). The aduit leurner: A neglected species, Houston: Gulf Publishing Company. (1974). The Modern practice of adult education. New York: Association Press.

Kolb. (1976). Leaming style inventory. Boston: McBer \& Co.

Lief, H. \& Reed, D. (1974). SKAT. Philadelphia: University of Pennsylvania.

Luckey, E.B. (1967). Helping children grow up sexualls.

Masters, W.H. \& Johnson, V.E. (1966). Human sexual response. Boston: Little Brown and Company.

McCary, J.L. (1967). Human seruality. New York: Van Nostrand.

Miller, S., Nunnally, E, \& Wockman, D. (1975). Alive and aware: Improving communication in relation. ships. Minneapolis: Interpersonal Communications Program.

National Sex Forum, (1975). Attitude restructuring. Sin Francisco.

Procopio, S. (1978), Education design skills. Paper presented at Curriculum Design Workshop, Concordia University, Montreal.

Satir, V. (1972). Peoplemaking, Palo Alto: Science and Behavior Books.

(1968). Cojoint family therapy. Palo Alto: Science and Behavior Books.

Segal, J. (1975). Peer counselor training manual. Pasadena, CA: Pasadena Planned Parenthood.

Wallum, L.R. (1977). The dynamics of sex and gender. Chicago: Rand McNally College Publishing Company. 